wanted to solve the ultimate problem, that of the physical basis of consciousness. The man who, in 1953, supposedly announced to drinkers in The Eagle pub in Cambridge that he had discovered the secret of life, was working in 2004, on his deathbed, on a paper proposing that the claustrum might be the key brain structure in producing consciousness. Olby works hard to put a positive spin on Crick's influence on consciousness research, in terms of support and the number of workers in the field. He stops short of suggesting that Crick was yet another great scientist who did not know when to retire and let younger people take over. Nevertheless, that conclusion could be drawn.

W. F. Bynum is emeritus professor of the history of medicine at University College London and author of The History of Medicine: A Very Short Introduction.

e-mail:w.bynum@ucl.ac.uk

\title{
How lateral thinking saved lives
}

\section{Martin Kemp is struck by the surreal quality of a home-made iron lung.}

There is no more-telling formula associated with surrealism than the words of the nineteenth-century French poet Comte de Lautréamont, who aspired to create something "as beautiful as the chance encounter of a sewing machine and an umbrella on an operating table".

Currently on show at the Mori Art Museum in Tokyo is the perfect surrealist object. A giant pair of bellows, of exactly the type used to resuscitate a domestic fire, is operated by a rude wooden lever that is pivoted on an arch of jointed pipes. It is tethered to a coffin-like wooden box, which is in turn anchored to a rickety iron bed. Patches on the leather lung of the bellows testify to its sustained use. On the wooden lid a series of stained rings speak of its occasional use as a table for hot beverages. It is a truly extraordinary object. To understand what it is really is - or was - we must return to the seventeenth century.

John Mayow, a physician at All Souls College at the University of Oxford, UK, was a member of the illustrious circle that included Christopher Wren, Robert Hooke and Thomas Willis, founder members of the Royal Society. Mayow's 1688 treatise On Respiration established the first mechanical basis for how humans breathe.

Mayow wrote that "if a bladder with most of the air pressed out of it, and tied by a tight ligature around the sphincter, be placed in a glass from which the air is afterwards exhausted, we shall at once see the bladder swell and become greatly distended," adding that it is "a rather pretty sight". The plate accompanying the treatise shows a pair of bellows to support his argument. Mayow, who also showed that the life-giving properties of air could be removed by combustion, died in 1679 aged 36, and is less well-known than he should be.

Given his early discovery of what came to be ponderously called external negative pressure ventilation, it is perhaps surprising that it was not until 1927 that a machine using this principle was invented to aid those whose respiratory systems were failing. The invention, which became known as the iron lung, is credited to the Harvard University physician Louis Agassiz Shaw and his colleague, the pioneer of industrial medicine, Philip Drinker. They had been sponsored in their research by the Consolidated Gas Company of New York. Their device consisted of an iron cabinet from which air could be evacuated by two vacuum-cleaner power units. It made a spectacularly successful debut on 12 October 1928 at Boston Children's Hospital in Massachusetts, where it resuscitated a child who had faced what seemed an inevitable death.

The iron lung, in its sleeker version as a polished or enamelled metal cylinder punctuated by windows and equipped with an angled mirror that allowed patients to see their surroundings, came into its own during the polio outbreaks of the 1940s and 1950s. The respirators enabled those whose chest muscles had been paralysed by the disease to breathe, and stood in diagonally serried rows in large wards while solicitous nurses filed by.

Anyone acquainted with such high-tech versions would barely recognize the wooden cabinet with bellows as an iron lung. Indeed, iron is not the most evident material used in the device. But it is indeed a respirator, and one that performed sterling service for a dozen or more years at the Lansdowne Hospital in Cardiff, UK, before being retired in the late 1950s. It seems that the bellows lung was put together by resourceful hospital engineers, presumably to save money. Only immediately available materials were used, such as wood, leather and tacks, and a hospital bed was commandeered. The whole ensemble declares the potency of artisanal resourcefulness.

The utilitarianism of the bellows lung chimes with surrealism in two respects. The first is that the leaps of lateral imagination that lay behind the incongruous juxtaposition of objects in surrealism find a clear parallel in the Welsh engineers' brilliant insight that a giant pair of traditional bellows could be combined with a wooden box and bed to do the same job as the manufactured item. The second is that how we look at an object varies over time and in settings other than those for which it was conceived. Now that the bellows lung features in historical displays, we cannot help but see it as a strange and wondrous thing alongside the other technological dinosaurs that fascinate us in museums of science.

Martin Kemp is emeritus professor in history of art at the University of Oxford, Oxford, UK.
This makeshift respirator was used in a UK hospital until the late 1950s.
The iron lung is on display at the Mori Art Museum in Tokyo until 28 February, and is part of the Science Museum's permanent collection in London. 